\title{
Knowledge management related training strategies in Kingdom of Saudi Arabia construction industry: An empirical study
}

\author{
Suresh Renukappa, Subashini Suresh and Hanouf Alosaimi \\ Faculty of Science and Engineering, \\ University of Wolverhampton, \\ Wolverhampton WV1 1LY, UK \\ Email: suresh.renukappa@wlv.ac.uk
}

\begin{abstract}
The growing popularity of knowledge management (KM) in the construction industry has, unfortunately, not been matched by parallel empirical research in training and benefits of KM for construction industry in the Kingdom of Saudi Arabia (KSA). This paper discusses the KM related training strategies implemented in the Kingdom of Saudi Arabia construction industry. Given the relatively new and unexplored nature of the research problem, qualitative research method was adopted to collect and analyse data. Results are based on the analysis of data from 46 professionals from KSA construction organisations. This paper concludes that training interventions are a complex and context-embedded activity. The current study results suggests that for effective implementation of KM strategies, there is an urgent need for KSA construction industry to develop and deploy appropriate $\mathrm{KM}$ related management training programmes. Leadership plays an important role in breaking down barriers in achieving KM strategies. The practical implication of this research is that the KM should not only focus on the specific knowledge to be captured, shared, mapped and transferred between individuals but should also address strategic concerns at group and organisational levels.
\end{abstract}

Keywords: Construction industry, Culture, Knowledge management, Kingdom of Saudi Arabia

\section{INTRODUCTION}

Saudi Arabian construction is worth $\$ 25.3$ billion and contributes approximately $20 \%$ of the Saudi Arabia GDP and has been growing tremendously (RnR Market Research, 2014). This is particularly important in the Saudi Arabian construction sector as the Saudi Arabian government is making large investments in its attempts to move towards becoming a knowledge-based society as highlighted in the visions of the Saudi Arabian National Policy Plan (Al Hussain et al., 2012). Alotaibi et al. (2013) links this to large construction projects being carried out by Saudi private and public sectors to keep up with the current rapid growth of the Saudi economy. Specifically, with respect to the construction industry, Yu et al., (2013) highlighted the complexity associated with knowledge-intensive environments of the construction industry where cumulative identification of experiences and knowledge differs on a day-to-day bias across engineers, projects and companies. Studies have reported that there is a need for effective knowledge management (KM) in the construction industry by reusing and sharing knowledge to improve quality, reduce time and cost of project completion and ultimately improve competitiveness (Ahmad and An, 2008; Yu et al., 2013).

The construction industry is one of the high risk industries that operate in an information-rich environment, which relies heavily on knowledge as one of the strategic resources to ensure the tasks associated with the domain can be performed effectively and efficiently by the project team members (Egbu and Robinson, 2005, Rezgui et al., 2010 and Yeung et al., 2016). Consequently, 
Khuzaimah and Hassan (2012) pointed out it is clear that knowledge must be deliberately and consciously managed in a systematic manner to enable organisations to avoid repetition of costly mistakes, to achieve improved performance and reinvention of wheels.

Nowadays, organisations employ KM as a part of their management strategies particularly, managing their tangible assets. Suresh et al. (2016) stated that construction organisations have been managing knowledge informally for years, but the challenges facing today's industry mean that most organisations need a more structured, coherent approach to KM. The process of managing knowledge in the construction industry is not a simple task and requires thorough planning and preparation. Due to the intrinsic characteristics of the construction industry that is highly fragmented and transient in nature (Khuzaimah and Hassan, 2012), the success rate of managing project knowledge has been somewhat minimal (Lin and Lin, 2006). Knowledge and its management will become increasingly important in organizations that are driven by ISO certification requirements. ISO 9001: 2015 was released in September 2015 which means that organizations have yet to apply the organizational knowledge clause. Wilson and Campbell (2016) work states that explicit and tacit knowledge are addressed by the ISO standards. Draft BS ISO 30401 Knowledge management systems was for public comments still 17th January 2018. It discusses the context of the organisation, leadership, planning, support, operation, performance evaluation and improvement.

Von Krogh, et al., (2000) grouped KM impact on organisational performance into three broad categories: risk minimisation, efficiency improvement and innovation. Risk minimisation is closely linked to identifying and holding onto the core competencies that the organisation has. In most construction organisations, people have been recognised as key holders of valuable knowledge. KM can minimise the risk of losing valuable knowledge by identifying, locating and capturing what is known by individuals and groups of employees that is critical for organisations survival. KM can also impact on people's learning, adaptability and job satisfaction (BecerraFernandez, et al., 2004). For example, KM can facilitate employees' creativity and group effectiveness through informal and formal socialisation.

According to Butler (2000) KM strategies are depending on motives of the organisation. For the construction organisations these motives could be: controlled innovation and change, cost focused, cost reduction, do more with less, reduce rework, improved productivity, staff reductions, and better reward regimes. Therefore, construction companies need to pay greater attention to their knowledge base and the way they use their existing knowledge to compete.

Alavi and Leidner (2001) defined KM as the systematic process of acquiring, organising and communicating knowledge both tacit and explicit of organisational members so that others may make use of it to be more effective and productive. Within the construction context the KM process has been perceived as the combination of a series of activities for identifying, capturing, sharing and using knowledge (Suresh et al., 2017). Indeed, KM strategies can help to avoid the repetition of similar mistakes from previous work and therefore improve work efficiency. In other words, KM strategies can avoid additional effort, reduce the time spent and save money (Kamara et al., 2002). For the purpose of this research, KM is defined as "a systematic and integrative process of coordinating the organisation-wide activities of mapping, capturing, and 
sharing knowledge by individuals and groups in pursuit of the major organisational sustainability goals and objectives".

Various construction organisations in Kingdom of Saudi Arabia (KSA) are engaged in the KM strategies for leveraging knowledge within the organisation and across the value chain. For successful KM implementation, it is essential for the KSA construction organisations to establish knowledge networks and develop an effective mechanism for knowledge mapping, capturing, and sharing (Swieringa and Wierdsma, 1992). Considering the prevailing and emerging political and economic conditions in KSA, the Vision 2030 presents several upcoming opportunities for the growth and development of the country. The Vision 2030 emphasises three pillars, firstly, the position of KSA to be central to the Arabian and the Islamic countries; secondly, determination of the country to emerge as a global investment powerhouse and transform the unique strategic location of the country into an international centre that connects the three continents: Europe, Asia and Africa. The focus in these areas opens numerous opportunities of growth and expansion for the organisations, which can capitalise on such opportunities by harnessing knowledge among the employees (Fakeeh, 2016). According to Whittom and Roy, (2009) KM is proved to be highly essential for the growth of organisations of Saudi Arabia.

For organisations to have the awareness of the opportunities and potential benefits from KM training is an important aspect. Twum-Darko and Harker (2017) in their work emphasized that training seems to be the catalyst for obtaining the buy-in from an organisational perspective, i.e. that an organisation at its inception is achieved through training as the first step toward formalising knowledge sharing processes. Tan (2015) explored the case of Singapore to illustrate how knowledge is managed at the construction industry level to correct for pervasive market failure in knowledge generation and dissemination. Author concludes that if current and new knowledge is to be effectively managed at the industry level, the Government needs to support knowledge generation and dissemination. At the level of individuals, there is asymmetric information in the quality of the training courses. Furthermore, Yeung et al (2016) illustrated the use of narratives to educate novices to learn from the past in a safe environment in the construction industry from where narratives for lessons learnt are costly and limited, as they are constructed from the occurrence of accidents. Although KM has been widely practiced in some countries, there is a little evidence in the KSA especially in the construction industry about training.

\section{Why training for KM?}

The aim of training is to change behaviour at the workplace in order to stimulate efficiency and higher performance standards (Cowling and Mailer, 1990).Training ensures the systematic development of the attitude, knowledge and skill behaviour pattern required by an employee in order to perform a given task adequately. Training programs yield many direct benefits such as enhanced problem-solving skills, a more competent and efficient workforce, fewer recruitment problems in obtaining qualifies employees and fewer problems with employee relations.

Tacit knowledge is more difficult to formalise, impart, exchange, or purchase because it resides in peoples' beliefs, experiences, values, organisational routines, and institutions (Huseman and Goodman, 1999). For example, in construction site safety, safety hazard recognisation is an important actualisation of tacit knowledge. Safety hazard knowledge is considered a tacit knowledge because it relies on the safety engineer's experience. Training is an area of Human 
Resources Management that deals with what people know and how they know; an issue of great importance in KM.

Lindstaedt and Zimmerman (2006) noted that most learning issues are dealt with by the human resources department, that's not necessarily the best department for this function, companybased learning needs to be embedded in business needs, so when a company changes its processes or procedures, the employee-training required to execute the changes develops in parallel. This kind of training can be provided within the main physical location of a company. Ideally, the main goal of internal training is to enhance the tacit knowledge that is the experimental knowledge of employees.

Yeung et al (2016) developed a training mechanism based on narratives. This was implemented for a statutory body in the construction industry in Hong Kong. It was based on narratives related to the falling of a person from height. The tacit knowledge of employees is particularly useful in addressing issues like identification of hazards, identification of waste sources, minimisation of waste, the management of emergency situations, managing relation with community, the development of preventive solutions, to name a few. It is therefore not easily codifiable and cannot be communicated or used without the individual who is the "knower". Tacit knowledge also tends to be sticky in nature. Von Hippel (1994) defined stickiness as the incremental expenditure involved in moving knowledge in a form that is useable and easily understood by the information seeker. According to Von Hippel, stickiness for the knowledge supplier comes from the tacitness of the knowledge that has to be shared, whereas absorptive capacity (organisations' or individuals ability to learn from external sources) creates stickiness for the knowledge user. Therefore, tacitness of knowledge is a natural barrier to the successful sharing of knowledge between individuals in organisations.

Many construction organisations are now engaging in $\mathrm{KM}$ in order to leverage knowledge both within their organisation and externally to their shareholders and customers. The Rethinking Construction report - "Respect for people: A framework for action" (Rethinking Construction, 2002) recommended that every firm and project should review it's induction training, so that the whole workforce receives details of organisational structure, immediate and long term aims, an explanation of standards and practices, rewards and penalties, and is provided with support through an effective mentoring approach.

Hughey and Mussnug (1997) noted that the underlying aim of all employee training is to increase efficiency. Mathieu et al. (1992) stated that individuals rely on training to improve their current skills and to learn new skills. It is necessary to understand the difference between training and education prior to the need for training in $\mathrm{KM}$ initiatives in the construction industry (Bordeianu, 2015). In distinguishing training from education, Morris (1971) considers training as the "use of specific learning, often with the use of techniques that can be identified and continually improved". For education, he noted that it is "a broader process of personal change in abilities and attitudes which may take place independently of its application of work".

Hari et al., (2005) defines training as teaching (a person or animal) a particular skill or type of behaviour through regular practice and instruction. The operational definition for training in this study adopts Armstrong's (1996) definition, which purports that training usually refers to learning a specific task or job, the skills and behaviours of which are specifically defined, whereas development is an ongoing process involving changing people. This implies that 
training is more of a mechanistic process, which is job-centred, while development involves educating the workforce, which is person-centred (Fryer, 2004). It is important to note this distinction in order not to use the terms interchangeably resulting in confusion.

Anecdotal evidence and empirical results (Curran and Stanworth, 1981) suggest that the lack of training in firms hinders growth. By reading a document or manual about their jobs and the organisation, and by reflecting upon it, trainees can internalise the explicit knowledge written in such documents to enrich their tacit base (Nonaka and Toyama, 2003).

Thiry (2004) suggests that training programmes are embedded into a complex context where cultural and competitiveness issues are often at odds with each other. Ulrick (1997) suggested that organisations need to be able to capture the tacit knowledge of its employees and to do this effectively; it is argued that management needs to involve and engage employees fully in the activities of the organisation. Therefore, the research question is: what are the current and future training strategies adopted and required for KM in KSA construction organisations enroute to enhance competitiveness.

\section{RESEARCH METHODOLOGY}

In order to achieve the research question, a robust methodology was considered essential. Gable (1994) argued that an explorative qualitative approach is better suited to study a nascent research field and gain valuable initial insights. Since the study was exploratory in nature and little was known about the subject under investigation, it was essential to select qualitative methods because they produce a wealth of detailed data and the data collection is not restricted to predetermined categories or themes (Hyde, 2000 and Amaratunga et al., 2002).

According to Bryman and Bell (2015), the qualitative method tends to be concerned with words rather than numbers. The findings of qualitative research are focused acknowledging the qualities of phenomena rather than their mathematical measurement. The qualitative method covers the subject of study holistically.

Semi-structured interviews were selected, due to flexibility they afford whilst still allowing detailed responses between the interviewer and the interviewee (Smart et al., 2014). The sampling method used is purposive or non-probability sampling, whereby the subjective judgements of the researcher are used in selecting the sample (Remenyi et al., 1998). Furthermore, a purposive sampling technique involves drawing samples that are both easily accessible and willing to participate in a study (Tashakkori and Teddlie, 2010). According to O'Leary (2004) non-probability sampling methods are used when there is need to answer the "how" and "why" questions. Therefore, a purposive sampling technique was used in order to achieve representativeness.

A total of 50 top construction organisations in KSA were contacted of which 30 organisations agreed to participate in this study. Firstly, the organisations were sent the invitation letter which stated about the research, ethical aspects of conducting interviews and the benefits of participating (i.e. sharing the summary of the results). Within the 30 organisations, the sample included directors, advisers and managers responsible for KM implementation in their respective organisations, as presented in Table 1. The participants were grouped by their job title: directors, 
advisors and managers. All the interviewees have considerable experience in the KSA construction sector; in particular they had relevant experience on knowledge management issues, with some of them having 'knowledge management' in their job titles.

\section{Insert Table 1 here}

An important sample size issue in qualitative research involves saturation of information (Strauss and Corbin, 1998). Mason (2010) analyses qualitative studies from $\mathrm{PhD}$ thesis and explains that such studies may have between four and eighty-seven interviews, with a mean value of twenty five. Creswell and Poth (2017) recommend twenty to sixty interviews for a study of this kind. The sample size of this study was based on the principles for data saturation theory explained by Francis et al. (2010). Saturation is a term used to describe the point when no new insights or range of ideas are generated through adding more data. In this study, data were collected until no new aspects of the KM related training strategies were revealed. In this study, actual saturation of data occurred before the 43 interview. Therefore, to ensure greater dependability and transferability (Creswell, 2014), a total of 46 professionals from $30 \mathrm{KSA}$ construction organisations were interviewed. The data was collected between July 2016 and December 2016. The interviews lasted between 30 and 90 minutes. The format of these interviews was face-toface, and the transcripts were recorded and supplemented with field notes as appropriate. The interviewees were asked the following questions which is reported in this paper: Q1. Are there any current KM specific training strategies in place in the KSA construction organisations? Q2. Are there any future KM specific training strategies needed in the KSA construction organisations your organisation?

Blismas and Dainty (2003) made a number of significant points with regards to the use of software packages for data management which are acknowledged: the restriction of the study imposed by a software; importance of understanding how the software package operates and what the weaknesses are so these can be addressed; to remember that the computer is only to aid the process; advantage of a software package is that all the data is contained 'within a single analytical environment'; a lot of work is required on the part of the researcher despite use of a software package; and importance of making any prejudices of the researcher apparent in the research explanation. Furthermore, in a comprehensive assessment by Morison and Moir (1998) on the pros and cons of using software for coding, limitations seemed to outweigh benefits. When purported efficiency of data management and retrieval capabilities were weighed against the potential loss of 'familiarity with the data engendered through repeated handling, reading and re-reading that is part of the analytical process itself distancing researcher from the data through mediation of computer software'. Therefore, it was decided that a better approach was to use paper, pen and the capabilities of Microsoft Word.

The analysis of the interviews was undertaken using Content Analysis. This type of analysis is practical when semi-structured questions are used in soliciting information, because it allows for defining content categories through coding. Selecting and defining categories (codes) is analogous to treating semi-structured questions as if they were closed-ended in survey research (Singleton and Straits, 2005).

Fraenkel and Wallen (2003) noted that content analysis is a study of textual messages of human behaviour in an indirect way. This helps researchers generalise findings, predict the future, understand attitudes, values and cultural patterns of an organisation or an industry or a country. 
In the study, coding of the transcribed documents involved open coding of meaning units, that is, words, phrases, sentences, paragraphs, which essentially involved labelling concepts. The emerging concepts were mapped into themes. The themes have been cross-checked on group discussions between the authors and two fellow researchers. Threats to validity were minimised through triangulation of data collection methods (interviews, internal and external documents) and verification of the initial thematic codes by participants, where they judged the accuracy of data collected, though not its conclusions (Tajeddini and Mueller, 2012). The unit of analysis adopted for this study was the KSA construction industry, and the embedded unit of assessment was the 'individual employee'.

\section{THE NATURE OF TRAINING PROVISION THAT CURRENTLY EXIST FOR KM IN KSA}

During the semi-structured interviews in this current study, the subject of training was raised, i.e. "in your organisation, is there any specific KM specific training programme in place"? The interviews with 46 professionals from the KSA construction organisations revealed seven types of KM specific training strategies adopted in the KSA construction organisations (see Table 2).

Insert Table 2 here

In this study, 63\% (29 of the 46) of the interviewees asserted that they had a training programmes specifically designed for KM implementation. Most often cited topics under the KM training programmes include: drivers for KM, strategies, sharing knowledge, identifying knowledge and storing knowledge. The interviewees also revealed instances where members of staff had to submit reports after attending external training. In one of the organisations, external training was encouraged, for which employee's paid $20 \%$ of the training fee and the remaining $80 \%$ was paid by the organisation. For instance, one of the interviewees in the current study had attended the training course titled, "improving business performance through knowledge management initiatives". The interviewee further noted that he now fully realises the importance of knowledge and the amount of key knowledge available within his organisation. He also thought that training within organisation, for KM, is very important and would be adopting mentoring as part of knowledge capture initiative.

In the study, for external training, KSA construction organisations would prefer a one hour training programme which deals with the benefits, challenges and case studies of other construction organisations who have successfully implemented knowledge management initiatives. The interviewees also said that most of the training programmes were hosted in Riyadh and hence they would prefer training to be conducted regionally. This would enable more employees in construction organisations to attend.

In other organisation, one of the interviewees suggested that they had in-house training for KM. The UK based CITB (1988) study which shows that most construction organisations prefer inhouse training courses to external courses. Findings from this study suggest that nearly 30 years after the CITB study, the attitude towards in-house training has not changed. Three reasons given for in-house training on KM are: In-house courses are cheaper than external courses; In-house courses are directly geared towards meeting the objectives/needs of the organization; and there seemed to be very little or no external courses focused on KM 
However, 37\% (17 of the 46) interviewees stated that they did not have any training (a specific to $\mathrm{KM}$ ). The reasons stated were: KM in construction industry is a specialised area and to the best of their knowledge; no external training providers offered courses in this area; Professionals had to make a case why particular training was important and how it would help the organisation. Hence, 17 interviewees said that they lacked the awareness of KM benefits and did not present a case to their management to attend KM training course. For instance, one of the interviewees stated that:

"Employees training programmes demand a significant investment in terms of both financial and human resources. Training can also take up a great deal of time which could adversely effects schedules and deadlines".

This was further emphasised by another organisation's manager who noted that training was a waste of time and did not feel the need to attend training because he felt he was too busy dealing with urgent tasks for the day-to-day survival of his organisation. Furthermore, interviewee noted that professionals in the construction industry are usually recruited because they are experienced and familiar with the industry; therefore there was no need for training specific to KM.

A literature review indicated that training for KM in specific business settings, had not been fully developed (Muscatello and Joseph, 2003). The current study results suggests that for effective implementation of KM strategies, there is an urgent need for KSA construction industry to develop and deploy appropriate KM related management training programme(s). The challenge, therefore, is for business schools and training consultants to bridge the wide gap in the market place. Continuing Professional Development (CPD) programme(s) and executive training programme(s) are valuable ways to raise knowledge management awareness. Education and training programmes should be re-orientated to cover aspects of knowledge, data and information; KM processes, technology and people; managing construction stakeholder knowledge; critical success factors; and benefits of KM strategies. The education and training should be dynamic and adaptable to the increasing changing needs of business, society and people at large.

In this study, $57 \%$ (26 of the 46) interviewees noted that they had a communication skills related training programmes. Most of these interviewees noted that communication training on the job is the most crucial factor. The interviewees stated that a wide range of communication related training programmes are undertaken by them to train the manager and the staff members within the organisation. Such training is said to be helpful for improving the skills and knowledge of the employees and improves their overall performance. For instance, one of the interviewees stated that:

"we have a perception that investment in communication skills will enables organisations to get an edge among the clients base."

Analysis of the above statement reveals that development of the communication skills and abilities of the employees is directly related to overall performance and client satisfaction for the organisation. 
In this study, 37\% (17 of the 46) interviewees noted that they had a time management related training programmes. For instance, one of the interviewees stated that:

"Properly implemented time management training programmes can help in harnessing their knowledge, building confidence and creating well-developed client services".

Analysis of the above statement reveals that development of the time management skills and abilities of the employees is directly related to overall performance and client satisfaction for the organisation.

The study findings are also in alignment with the literature which states asserts that employee communication and time management training pays a highly significant role in the improving the performance and the productivity of the employees. Such consistent training programmes also serve to be useful in enhancing the knowledge, attitudes of the employees, skills, thereby encouraging the growth and development of the employees skills (Nassazi, 2013; Hafeez and Akbar, 2015; Facteau, et al. 1995).

In this study, 37\% (17 of the 46) interviewees noted that they had a on the job training and $19 \%$ (9 of the 46) interviewees noted that they had a mentoring scheme. For instance, one of the interviewees noted that:

"Some of the most critically important training programs include communication skills, leadership training, mentoring and on the Job training".

Similarly, other interviewee stated that:

"On the job training, mentoring, communication skills, customer service etc. are the training and education programs we have for the employees within our company. Our organisation beliefs on the job training can provide employees with more knowledge hence supports it."

The study findings thus indicate the application of on the job training, mentoring and skills development as the key training activities currently undertaken by the organisations to impart skills and knowledge to the employees. For instance, the examination of the literature on the role of mentoring reveals that it serves as a highly pertinent strategy to improve the performance of the employee and the organisation. The literature has also highlighted that unlike other training methods, mentoring relationship with the manager enables a close supervision that helps in developing skills, gaining knowledge and address gaps in the current ability (Allen, et al. 2004; DeMik, 2007; OPM, 2008; Nonaka and Takeuchi, 2011; Elnaga and Imran, 2013). These findings indicate the significance of mentoring for improving the performance of the employees and supporting the learning and development of motivated employees who are seeking to gain professional and personal growth.

The findings of the interview further revealed that leadership skills (19\%) are also considered to be current KM specific training programmes. Leadership skills development is as a key training method currently adopted by the small number of interviewed organisations. The literature also identifies leadership as an effective method as it encourages the employees to inculcate essential skills related to decision making and exploring adequate solutions for the emerging challenges 
with higher efficiency (Nonaka and Takeuchi, 2011; Kraus and Wilson, 2012; and Jahenzeb and Bashir, 2013). Based on these findings, it can be interpreted that leadership skills are useful and efficacious methods currently adopted by the organisations in their training programmes that has a positive impact on KM within the KSA construction organisations. However, the lack of leadership skills is one of the most important challenges organisations face in implementing KM related change initiatives.

In this study, 19\% (9 of the 46) interviewees noted that they had a client management related training programmes which is of the crucial factors that influence KM within an organisation. In this respect, one of the interviewees noted that the role of client/customer services as a part of training programme, and thus makes a key impact on the contribution of the KM initiatives. In this respect, the literature also confirms with these findings and asserts that effective training in delivering high level client/costumer service plays a key role in enhancing KM within an organisation and thus highlights the significance of the role of human resource on KM (Clardy, 2012; Baldwin., et al. 1991). Further, the findings of the interview also revealed that the KM has a significant impact on the employees in gaining skills for providing efficient client/customer services and thus enhances the overall productivity of the organisation.

\section{THE FUTURE TRAINING RELATED TO KM IN KSA}

The interviewees were asked to volunteer information on the nature of training for KM in the next 5 years considering how their jobs are likely to change in the future. The study revealed five types of future KM specific training strategies needed in the KSA construction organisations (see Table 3).

\section{Insert Table 3 here}

Of the interviewees, $80 \%$ (37 of the 46) noted that training programmes related to capturing knowledge is the way forward for the KSA construction industry. During the interviews, most of the participants realised that there was immense knowledge embedded in their organisations, but they lack awareness and understanding on how to capture knowledge. They also suggested that mentoring/coaching, apprenticeship and job rotations were means of capturing organisational tacit knowledge. For capturing explicit knowledge, the efficient use of technology was thought to be useful. For example, through indexing and archiving best and worst practices in various projects. The interviewees also noted that knowledge capture and codification are particularly critical when an issue of knowledge continuity arises.

For instance, one of the interviewees thought that there is a need for formalised training programmes to "collect and obtain" past and present knowledge from an individual, group or organisation in order to improve organisational competitiveness. Three of the interviewees suggested a formalised training programme using knowledge capture training metrics of input or output indicators which could be used to monitor the performance of knowledge assets. On the input side, the indicators should reflect enablers or actions required to implement or achieve business objectives. Examples of input indicators are number of training days per employee, proportion of staff with professional qualifications or with over two years' experience, and senior managers with experience on major projects. The output indicators should measure the 
performance or the result of those actions, such as the number of defects after project completion, complaints from clients, and cost and time overruns".

Four of the interviewees suggested that motivation for increasing their skills seems to be lacking because they do not believe the organisation values training. This may be because the organisation has not provided an incentive or a vehicle that meets their particular needs. Training in non-working hours is considered to be difficult because the employees have other demands on their time. Facteau et al.'s., (1995) study indicates that motivation has an important influence on the extent to which trainees actually learn the material presented to them during a training program. Baldwin et al.'s., (1991) study found that motivation may influence important training outcomes such as performance appraisals. The construction industry has a belief that the approach of motivating employees to give effective performance may lead to enhance their performance as well as the performance of the organisation (Dries, 2013). None of the interviewed organisations noted any influence of training on performance appraisals.

In the study, $70 \%$ (32 of the 46) of the interviewees noted that training programmes related to sharing knowledge is the way forward for the KSA construction industry. For instance, one of the interviewees noted that sharing knowledge is a major challenge for their organisations due to a variety of reasons; therefore, there is a need to understand it further. Knowledge sharing behaviours facilitate learning among employees and enable them to resolve problems similar to situations encountered by others in the past, thus enabling quicker responses to the clients (Sher and Lee, 2004). Such behaviours may, in some circumstances, stimulate other individuals to capture new knowledge (Ipe, 2003). Furthermore, knowledge sharing activities are of utmost importance for knowledge retention because when employees leave an organisation their knowledge leaves with them (Bender and Fish, 2000). Although knowledge exists at different levels of an organisation, for instance, at the individual, team, and organisation levels, sharing of knowledge at the individual level is critical to an organisation. However, national and organisational cultural characteristics play a key role in successful knowledge sharing process.

Of the interviewees, $57 \%$ (26 of the 46) stated that creating culture for the knowledge management is the way forward for the KSA construction industry. Arif et al. (2015) argued national culture as one of the major barriers to effective KM practices. However, MagnierWatanabe and Senoo (2008) found organisational characteristics to be a stronger prescriptive factor in KM compared to national culture. De Long and Fahey (2000) suggested four ways in which culture affects the behaviours central to knowledge creation, sharing and use. First, culture shapes assumptions about what knowledge is and which knowledge is worth managing. Second, culture identifies the relationships between individual and organisational knowledge, determining who is expected to control specific knowledge, who must share it and who can store it. Third, culture shapes the processes by which new knowledge is created, legitimised and distributed in firms. Fourth, culture creates the context for social interaction that determines how knowledge will be used in particular situations.

Serna (2015) suggested that knowledge should be managed along with the human experience of knowledge itself and that proper management of such knowledge is required. Hofstede (2001) suggests that there would be a significant impact of culture on management practices and processes. Therefore, it is important to incorporate the cultural aspects in the future training programmes related to KM in the KSA construction industry. 
In the study, $44 \%$ (20 of the 46) of the interviewees noted that training programmes related to mapping knowledge is the way forward for the KSA construction industry. Skyrme and Amidon (1997) noted, most research attention has been given to KM within the organisation, and knowledge mapping remains an emergent research issue. Knowledge mapping is the field within KM that aims to optimise the efficient and effective use of the organisation's knowledge. Davenport and Prusak (1998) note that developing a knowledge map involves locating important knowledge within the organisation and then publishing some sort of list or picture that shows where to find it. Knowledge maps typically point to people as well as to documents and databases.

Effective knowledge maps should point not only to people but to documents and databases as well. Knowledge maps should also locate actionable information, identify domain experts, and facilitate organisation-wide learning (Eppler, 2003). They should also trace the acquisition and loss of knowledge, as well as map knowledge flows throughout the organisation (Grey, 1999). Therefore, it is important to incorporate the knowledge mapping concepts in the future training programs related to KM in the KSA construction industry.

Of the interviewees, $33 \%$ (15 of the 46) stated that efficient use of KM tools is the way forward for the KSA construction industry. The current business environments are characterised by globalization, dynamism and increasing levels of complexity due to rapid changes in technology and its connected intricate knowledge (Siakas et al., 2010). However, the KSA construction sector has been slow to recognize the benefits of information technology (IT) as a major communication tool. There are several issues with the current use of technologies in the interest of KM. The challenge for technology is to facilitate a dynamic process of knowledge creation and representation, not a static process of information management. Current IT based KM technologies focuses only on explicit knowledge, which can be expressed in words and numbers and easily shared, and fails to deal with tacit knowledge. Therefore, it is important to incorporate the $\mathrm{KM}$ tools and its concepts in the future training programs related to $\mathrm{KM}$ in the $\mathrm{KSA}$ construction industry.

\section{CONCLUSIONS}

Knowledge has now become widely recognised and accepted as a valuable organisational resource in the business world. The KM programmes have been used in the KSA construction organisations at different levels of implementation. Training is an essential process that develops three dimensions of the knowledge of employees of the organisation that are competence, knowledge and exploitative knowledge. As revealed by the study:

- current training programmes specifically designed for KM in the KSA construction industry include: communication skills, time management skills, training on-the-job, mentoring, leadership skills and client management.

- the nature of future training for KM include: capturing knowledge, sharing knowledge, creating culture for KM, knowledge mapping, and efficient use of KM tools.

The current study results suggest that for effective implementation of KM strategies:

- there is an urgent need for KSA construction industry to develop and deploy appropriate KM related management training programmes. 
- The challenge, therefore, is for business schools and training consultants to bridge the wide gap in the market place. Continuing Professional Development (CPD) programmes and executive training programmes are valuable ways to raise $\mathrm{KM}$ awareness.

- Leadership plays an important role in breaking down barriers in achieving KM goals barriers such as tunnel vision, past practice, old ideas and cultural frameworks that together combine to discourage new visions of the future.

- Leadership is about preparing organisation with a $\mathrm{KM}$ vision and values that resonate with the team, employees, and key stakeholders. Therefore, there is an urgent need to develop and deliver a bespoke training framework to address, improve and measure the effectiveness of leadership skills for implementing KM related change initiatives in the KSA construction industry.

The practical implication of this research is that the KM should not only focus on the specific knowledge to be captured, shared, mapped and transferred between individuals but should also address strategic concerns at group and organisational levels. Therefore, construction organisations in the KSA must also hone in on these basic modern day truths and implement KM training programmes which focus both on tacit and explicit knowledge. To gain competitive advantage, it is necessary for KSA construction industry to recognise and use a blend of ICT and non-ICT based KM tools. It is advisable to use conventional, simple, low cost, and easy to use with minimum training needs KM techniques and technologies such as mentoring and on-the-job training strategies.

This research has made significant contributions to knowledge since there is no previous research explored on KM related training programmes in the KSA construction organisations. This study is representative to KSA construction industry given that the research reported in this paper is largely exploratory by nature, the results presented here are only tentative and of limited value for the purpose of generalisability. Furthermore, findings of this paper are limited to the KSA construction industry context only, as such, the level of generalisability outside this context may be very limited. However, Gulf Cooperation Council (GCC) countries that is similar to the study area, and hence the findings could apply to them in some way.

\section{REFERENCES}

Ahmad, H. S. and An, M. (2008). Knowledge management implementation in construction projects: a KM model for Knowledge Creation, Collection and Updating (KCCU). International Journal of Project Organisation and Management, 1(2), 133-166.

Alavi, M. and Leidner, D. (1999). Knowledge Management Systems: Emerging Views and Practices from the Field. Proceedings of the 32nd Annual Hawaii International Conference on System Sciences: Hicss-32, Hawaii International Conference on System Sciences// Proceedings.

Alavi, M. and Leidner, D.E. (2001) Knowledge management and knowledge management systems: conceptual foundations and research issues, MIS Quarterly, Vol. 25, No. 1, pp.107-136. 
ALHussain, A., Murphreem E. and Bixler, C. (2012). Barriers to Knowledge Management in Saudi Arabia. Journal of Knowledge Globalisation, 5(1), 1-12.

Allen, T. D., Poteet, M. L., Eby, L. T., Lentz, E. and Lima, L. (2004). Career benefits associated with mentoring for protégés: A meta-analysis. Journal of Applied Psychology, 89, 127-136.

Alotaibi, H., Crowder, R. and Wills, G. (2013). Investigating Factors for Knowledge Sharing Using Web Technologies. Proceedings of the 13th International Conference on Knowledge Management and Knowledge Technologies, Graz, Austria, September 04 - 06, 2013.

Amaratunga, D., Baldry, D., Sarshar, M., and Newton, R. (2002) Quantitative and qualitative research in the built environment: Application of "mixed"' research approach, Work Study, 51(1), 117-131.

Andriessen, D. (2004). Intellectual Capital Valuation \& Measurement: State of the Art. Journal of Intellectual Capital, 2, 230-242.

Arif, M., Mohammed, A. and Gupta, A. (2015). Understanding knowledge sharing in the Jordanian construction industry. Construction Innovation, 15(3), 333-354.

Armstrong, M. (1996). A Handbook of Personnel Management, London, UK: Kogan Page.

Baldwin, T. T., Magjuka, R. J. and Loher, B. T. (1991). The perils of participation: effects of choice of training on trainee motivation and learning. Personnel Psychology, 44, 51-66.

Baldwin, T. T., Magjuka, R. J., and Loher, B. T. (1991). The perils of participation: Effects of choice of training on training motivation and learning. Personnel Psychology, 44, 51-66.

Becerra-Fernandez, I., Gonzales, A. and Sabherwal, R. (2004) Knowledge management: Challenges, solutions, and technologies, Pearson Education, New Jersey.

Bender, S. and Fish, A. (2000). The transfer of knowledge and the retention of expertise: the continuing need for global assignment. Journal of Knowledge Management, 4(2), 125-137.

Blismas, N. G. and Dainty, A. R. J. (2003) Computer-aided qualitative data analysis: Panacea or Paradox?, Building Research and Information, 31 (6), 455-463.

Bordeianu, O.M. (2015). The role of knowledge management and knowledge management strategies within learning organisations. Ecoforum, 4, 147-154.

Brooking, A. (1998). Corporate Memory: Strategies For Knowledge Management. London, UK: International Thomson Publishing.

Bryman, A. and Bell, E. (2015). Business Research Methods. New York, USA:Oxford University Press.

Butler, Y. (2000). Knowledge management-If only you knew what you knew. Australian Library Journal, 1, 31-42. 
CITB. (1988). Survey of supervisory and management training needs in the U.K. Construction Industry, 1(2), 1-10.

Clardy, A. (2012). The Management Training Tool Kit: 35 Exercises to Prepare Managers for the Challenges They Face Every Day. New York, USA: Pearson Publications.

Collis, J. and Hussey, R. (2003). Business Research: a practical guide for undergraduate and postgraduate students. Basingstoke, UK: Palgrave Macmillan publisher.

Cowlin, A and Mailer, C (1990) Managing human resources, London: Edward Arnold.

Creswell, J. W. (2014). Research Design: Qualitative, Quantitative, and Mixed Methods Approaches. New York, USA: Sage publishing.

Creswell, J.W. and Poth, C.N. (2017) Qualitative inquiry and research design: Choosing among five approaches, Thousand Oaks, CA: Sage publications.

Curran, J. and Stanworth, J. (1981). The social dynamics of the small manufacturing enterprises. Journal of Management Studies, 18(2), 141-158.

Davenport, H. (1994). Saving IT's Soul: Human Centered Information Management. Harvard Business Review, 72(2), 119-131.

Davenport, T. H. and Prusak, L. (1998). Working knowledge - How organisations manage what they know. Boston, MA: Harvard business school press.

De Long, D. W. and Fahey, L. (2000). Diagnosing cultural barriers to knowledge management. Academy of Management Executive, 14(4), 113-128.

DeMik, J. R. (2007). Coaching, counselling and mentoring: A strategic need in training and development. Retrieved November 15, 2016, from http://files.eric.ed.gov/fulltext/ED504505

Dries, N. (2013). The psychology of talent management: A review and research agenda. Human Resource Management Review, 23(4), 272-285.

Duhon, B. (1998). It's All in our Heads. Inform, 12 (8), 8-13.

Egbu, C. O., and Robinson, H. S., (2005) Construction as a Knowledge-Based Industry, in Anumba, C. J., Egbu, C. O., and Carrillo, P. M., Knowledge Management in Construction, Blackwell Publishing, Oxford.

Egbu, C., Kurul, E., Quintas, P., Hutchinson, V., Anumba, C. and Ruikar, K. (2003). Techniques \& Technologies for Knowledge Management, Retrieved November 15, 2016, from http://www.knowledgemanagement.uk.net/resources/WP3\%20Interim\%20Report.pdf

Elnaga, A. and Imran, A. (2013). The effect of training on employee performance. European Journal of Business and Management, 5(4), 137-147.

Emmerik, H. V. (2004). For better and for worse: adverse working conditions and the beneficial effects of mentoring. Career Development International, 9(4), 358-373. 
Eppler, M. (2003). Making Knowledge Visible through Knowledge Maps: Concepts, Elements, Cases. In Holsapple, C. W. (Ed.) Handbook on Knowledge Management, Vol.1, (pp. 189 - 205), Berlin, Germany: Springer-Verla publishing.

Facteau, J. D., Dobbins, G. H., Russell, J. E., Ladd, R. T. and Kudish, J. D. (1995). The influence of general perceptions of the training environment on pretraining motivation and perceived training transfer. Journal of Management, 21(1), 1-25.

Facteau, J. D., Dobbins, G.H., Russell, J. E. A., Ladd, R. T., and Kudisch, J. D. (1995). The influence of general perceptions of the training environment on pretraining motivation and perceived training transfer. Journal of Management, 21, 1-25.

Fakeeh, K. A. (2016). KSA 2030 Vision (Kingdom of Saudi Arabia's 2030 project) and its focus on families and students. International Journal of Computer Applications, 149, 46-48.

Firestone, J. M. (2008). On doing knowledge management. Knowledge Management Research \& Practice. 6, 13-22.

Fraenkel, J. R. and Wallen, N. E. (2003). How to design and evaluate research in education, New York: USA: McGraw-Hill Companies Inc.

Fryer, B. (2004). The Practice of Construction Management, London, U.K.: Sage publishing.

Gable, G. (1994). Integrating case study and survey research methods: an example in information systems. European Journal of Information Systems, 3(2), 112-126.

Grey, D. (1999). Knowledge mapping: A practical overview. Retrieved March 10, 2016, from http://www.smithweaversmith.com/knowledg2.htm

Groff, T. and Jones, T. (2003). Introduction to Knowledge Management. New York: USA: Routledge.

Hafeez, U. and Akbar, W. (2015). Impact of Training on Employees Performance. Retrieved December 5, 2016, from

www.macrothink.org/journal/index.php/bms/article/download/7804/6355.

Hari, S, Egbu, C and Kumar, B. (2005). A knowledge capture awareness tool: an empirical study on small and medium enterprises in the construction industry. Engineering, Construction and Architectural Management, 12 (6), 533-567.

Hedlund (1994). A model of knowledge management and the N-form corporation. Strategic Management Journal, 15(2), 73-90.

Hofstede, G. (2001). National culture and organizational practices. In Ashkanasy, N. (Ed.), Handbook on Organizational Culture and Climate, (pp. 21-22), Thousand Oaks, CA: Sage Publications.

Hughey, M. and Mussnug, N. (1997). Designing effective employee training programmes. Training for Quality, 5(2), 52-57. 
Huseman, C. R. and Goodman, P. J. (1999) Leading with knowledge: The nature of competition in the 21 st century, Sage publications, London.

Hyde, K.F. (2000). Recognising deductive processes in qualitative research. Qualitative Market Research: An International Journal, 3(2), 82-90.

Ipe, M. (2003). Knowledge sharing in organizations: A conceptual framework. Human Resource Development Review, 2(4), 337-359.

Jahenzeb, K. and Bashir, N. A. (2013). Training and development program and its benefits to employees and organisation: A conceptual study. European Journal of Business and Management, 5(2), 243-252.

Jennex M. E. (2007). Knowledge Management in Modern Organizations. London, UK: IGI Global.

Kamara J., Anumba C. and Carrillo P.M. (2002) A CLEVER approach to selecting a knowledge management strategy, International Journal of Project Management, Vol. 20, No. 3, pp.205-211.

Khuzaimah, K. H., and Hassan, F. (2012) Uncovering tacit knowledge in construction industry: communities of practice approach, Procedia - Social and Behavioral Sciences, 50(1), 343 - 349.

Kraus, A. J. and Wilson, C. N. (2012). Leadership development for organizational success. Retrieved January 5, 2017, from http://www.siop.org/WhitePapers/Visibility/LeadershipDevelopment.pdf

Laudon, K. C. and Laudon, J. P. (1998). Management Information Systems: New Approaches to Organization and Technology. Upper Saddle River, NJ: Prentice Hall.

Lin, Y.C. and Lin, L.K. (2006). Critical Success Factors for Knowledge Management Studies in Construction. ISARC Proceedings.

Lindstaedt, S. and Zimmermann, V. (2006), Managing knowledge for the new economy, IST Results, available at: www.istresults.cordis.lu

Magnier-Watanabe, R. and Senoo, D. (2008). Organizational characteristics as prescriptive factors of knowledge management initiatives. Journal of Knowledge Management, 12(1), 21-36.

Mason, M. (2010) Sample size and saturation in PhD studies using qualitative interviews, Forum: qualitative social research, 11 (3), 1-19.

Mathieu, J. E., Tannenbaum, S. I. and Salas, E. (1992). Influences of individual and situational characteristics on measures of training effectiveness. Academy of Management Journal, 35(4), 828-47.

McElroy, M. (1999). The Second Generation of Knowledge Management. Knowledge Management, 86-88.

Morris, J. (1971). Management development and development management. Personnel Review, 1(1), 30-43. 
Morrison, M. and Moir, J. (1998) The role of computer software in the analysis of qualitative data: Efficient clerk, research assistant or trojan horse?, Journal of Advanced Nursing, 28 (1), 106-116.

Muscatello, R. and Joseph, A. (2003). The potential use of knowledge management for training: A review and directions for future research. Business Process Management Journal, 9(3), 382394.

Nassazi, A. (2013). Effects of training on employee performance. Retrieved January 5, 2017, from http://theseus32-kk.lib.helsinki.fi/bitstream/handle/10024/67401/THESIS.pdf?sequence=1

Nonaka, I. and Toyama, R. (2003). The knowledge-creating theory revisited: knowledge creation as synthesizing process. Knowledge management research and practice, 1(1), 2-10.

Nonaka, I; and Takeuchi, H. (2011). The Wise Leader. Harvard Business Review, May;

O'dell, C. and Grayson, J. (1998). If Only We Knew What We Know: The Transfer of Internal Knowledge and Best Practice. New York, USA: Free Press.

OPM. (2008). Best practices: Mentoring. Retrieved January 15, 2016, from https://www.opm.gov/policy-data-oversight/training-and-development/careerdevelopment/bestpractices-mentoring.pdf

Pettrash, G. (1996). Managing knowledge assets for value. Proceedings of the Knowledge-Based Leadership Conference. Boston, MA.

Rezgui, Y., Hopfe, C.J. and Vorakulpipat, C. (2010) Generation of knowledge management in the architecture, engineering and construction industry: an evolutionary perspective, Advanced Engineering Informatics, Vol. 24, No. 2, pp.219-228.

RnR Market Research (2014). Saudi Arabia Construction Industry. Retrieved October 3, 2016, from www.prnewswire.com/news-releases/saudi-arabia-construction-industry-1098-cagrforecast-to-2018-285917141.html.

Serna, E. (2015). Maturity model of transdisciplinary knowledge management. International Journal of Information Management, 35(6), 647-654.

Sher, P. J., and Lee, V. C. (2004). Information technology as a facilitator for enhancing dynamic capabilities through knowledge management. Information \& Management, 41(8), 933-945.

Siakas, K.V., Georgiadou, E. \& Balstrup, B. (2010). Cultural impacts on knowledge sharing: empirical data from EU project collaboration. Vine, 40(3-4), 376-389.

Singleton, R. and Straits, B. (2005) Approaches to Social Research, Oxford University Press, London.

Skapinker, M. (1999). Knowledge Management: The Change Agenda, Chartered Institute of Personnel and Development, London, UK. 
Skyrme, D. J. and Amidon, D. M. (1997). The knowledge agenda. Journal of Knowledge Management, 1(1), 27-37.

Smart, D.W., Stojanovic, T.A. and Warren, C.R. (2014). Is EIA part of the wind power planning problem?. Environmental Impact Assessment Review, 49, 3-23.

Stankosky, M. (2011). Creating the Discipline of Knowledge Management. London, UK: Taylor \& Francis.

Strauss, A., and Corbin, J. (1998) Basics of qualitative research: Techniques and procedures for developing grounded theory, Thousand Oaks, CA: Sage.

Suresh, S., Oayinka, R., Chinyio, E. and Renukappa, S. (2017) Impact of knowledge management practices on construction projects, Proceedings of the Institution of Civil Engineers - Management, Procurement and Law, Vol. 170, No. 1, pp.27-43.

Suresh, S., Olayinka, R., Chinyio, E., and Renukappa, S. (2016). Impact of knowledge management practices on construction projects. Proceedings of the Institution of Civil Engineers - Management, Procurement and Law. 169(6), 1-17.

Swieringa, J. and Wierdsma, A. (1992). Becoming a Learning Organization: Beyond the Learning Curve. Workingham, U.K: Addison-Wesley.

Tajeddini, K. and Mueller. S.L. (2012) 'Corporate entrepreneurship in Switzerland: evidence from a case study of Swiss watch manufacturers', International Entrepreneurship and Management Journal, Vol. 8, No. 3, pp.355-372.

Tan, W (2015) Knowledge management in the construction industry: The strategy of Singapore, International Journal of Construction Management, 15, No.1, 10-16.

Tashakkori, A. and Teddlie, C. (Eds.) (2010). Handbook of mixed methods in social and behavioral research, Thousand Oaks, CA: Sage publishing.

Thiry, M. (2004). How can the benefits of PM training programs be improved. International Journal of Project Management. 22, 13-18.

Timetric (2014). Construction in Saudi Arabia - Key Trends and Opportunities to 2018. Retrieved March 30, 2016, from marketresearch.com.

Tiwana, A. (2000). The Knowledge Management Toolkit, New Jersey, USA: Prentice Hall.

Ulrick, D. (1997). Organising around capabilities. In Hesselbein, F., Goldsmith, M., \& Beckhard, R., (Eds). The organization of the future. San Francisco, USA: Jossey-Bass publishing.

Vol. 89 (5), PP. 58-67, 146.

von Hippel, E. (1994) Sticky information and the locus of problem solving: Implications for innovation, Management science, 40, 429-439. 
Von Krogh, G., Ichijo, K. and Nonaka, I. (2000) Enabling Knowledge creation. Oxford University Press, New York.

Whittom, A. and Roy, M.C. (2009). Considering participant motivation in knowledge management projects. Journal of Knowledge Management Practice. 10(1), 20-35.

Yu, Y., Hao, J., Dong. X. and Khalifa, M. (2013). A multilevel model for effects of social capital and knowledge sharing in knowledge-intensive work teams. International Journal of Information Management, 33 (5), 780-790. 
Table1: A breakdown of professionals who were interviewed for the study

\begin{tabular}{lc}
\hline Responsibility of interviewee in the organization & $\begin{array}{c}\text { No. of } \\
\text { Interviews }\end{array}$ \\
\hline Directors & 4 \\
- Project directors & 3 \\
- Associate director & 4 \\
- Director of supply chain & 2 \\
- Procurement director & 2 \\
- Operations director & 3 \\
- Human resources director & \\
Advisors & 4 \\
- Construction project advisor & 3 \\
- Knowledge management adviser & 2 \\
- Quality, Health, Safety and Environmental & \\
advisor & \\
Managers & 2 \\
- Senior Human Resources Manager & 3 \\
- Construction Manager & 4 \\
- 19Human resources manager & 3 \\
- Operations Manager & 2 \\
- Building Information Manager & 3 \\
- Knowledge management manager & 2 \\
- Construction supply chain manager & $\mathbf{4 6}$ \\
\hline
\end{tabular}

Table 2: Current KM specific training strategies adopted in the KSA construction organisations

\begin{tabular}{|c|c|c|c|}
\hline $\begin{array}{l}\text { SI } \\
\text { No }\end{array}$ & Current KM specific training strategies & $\begin{array}{l}\text { Total number of } \\
\text { interviewees cited }(\mathrm{N}=46)\end{array}$ & $\begin{array}{l}\text { Percentage } \\
\text { interviewees } \\
\text { cited }(\%)\end{array}$ \\
\hline 1 & Training programmes specifically designed for KM & 29 & $63 \%$ \\
\hline 2 & Communication skills & 26 & $57 \%$ \\
\hline 3 & Time management skills & 17 & $37 \%$ \\
\hline 4 & Training on-the-job & 17 & $37 \%$ \\
\hline 5 & Mentoring & 9 & $19 \%$ \\
\hline 6 & Leadership skills & 9 & $19 \%$ \\
\hline 7 & Client management & 9 & $19 \%$ \\
\hline
\end{tabular}

Table 3: Future KM specific training strategies needed in the KSA construction organisations

\begin{tabular}{llll}
\hline $\begin{array}{l}\text { SI } \\
\text { No }\end{array}$ & Future KM specific training strategies & $\begin{array}{l}\text { Total number of interviewees } \\
\text { cited }(\mathbf{N = 4 6 )}\end{array}$ & $\begin{array}{l}\text { Percentage } \\
\text { interviewees } \\
\text { cited (\%) }\end{array}$ \\
\hline 1 & Capturing knowledge & 37 & $80 \%$ \\
2 & Sharing knowledge & 32 & $70 \%$ \\
3 & Creating culture for KM & 26 & $57 \%$ \\
4 & Knowledge mapping & 20 & $44 \%$ \\
5 & Efficient use of KM tools & 15 & $33 \%$ \\
\hline
\end{tabular}

